\title{
Cyclohexyl-Substituted Polyglycolides with High Glass Transition Temperatures
}

\author{
Feng Jing, Milton R. Smith III, and Gregory L. Baker \\ Department of Chemistry, Michigan State University, East Lansing, Michigan 48824
}

Figure S1 $500 \mathrm{MHz}{ }^{1} \mathrm{H}$ NMR spectra of poly(rac-methylcyclohexylglycolide) 2

Figure S2 DSC runs (second heating scan after flash quenching from $120^{\circ} \mathrm{C}$ ) for 3 substituted polyglycolides. Heating rate: $10^{\circ} \mathrm{C} / \mathrm{min}$ under nitrogen.

Figure S3 DSC runs (second heating scan after flash quenching from $120^{\circ} \mathrm{C}$ ) for $\quad 4$ poly(dicyclohexylglycolide)s. Heating rate: $10^{\circ} \mathrm{C} / \mathrm{min}$ under nitrogen.

Figure S4 Linear viscoelastic properties of dicyclohexylglycolide at $170{ }^{\circ} \mathrm{C}\left(\mathrm{M}_{\mathrm{w}}=85 \quad 5\right.$ $\mathrm{Kg} / \mathrm{mol}$, PDI $=1.46)$.

Figure S5 $125 \mathrm{MHz}{ }^{13} \mathrm{C}$ NMR spectrum of the carbonyl region for solution 5 polymerized $R$, $R$-dicyclohexylglycolide. 


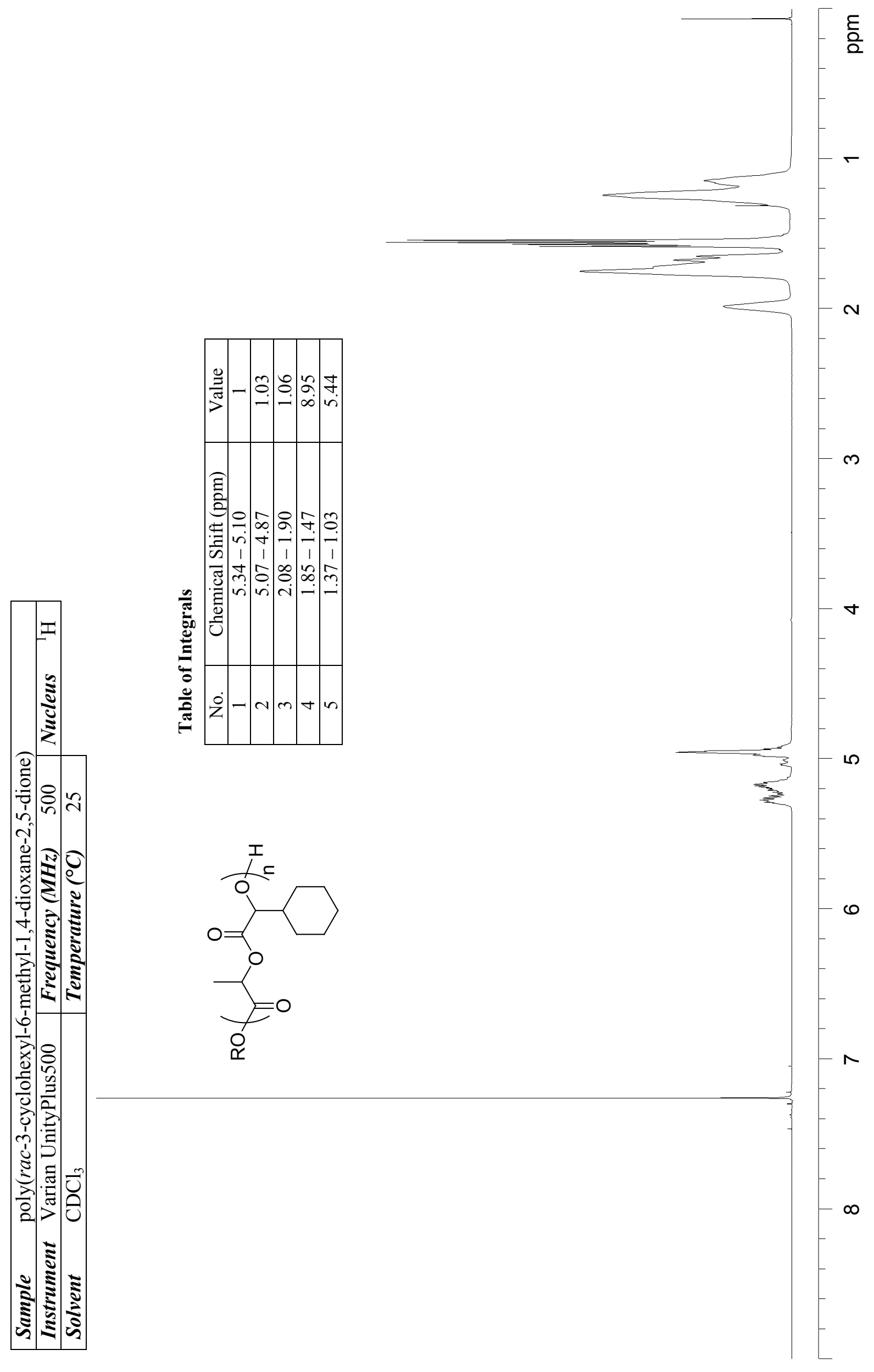




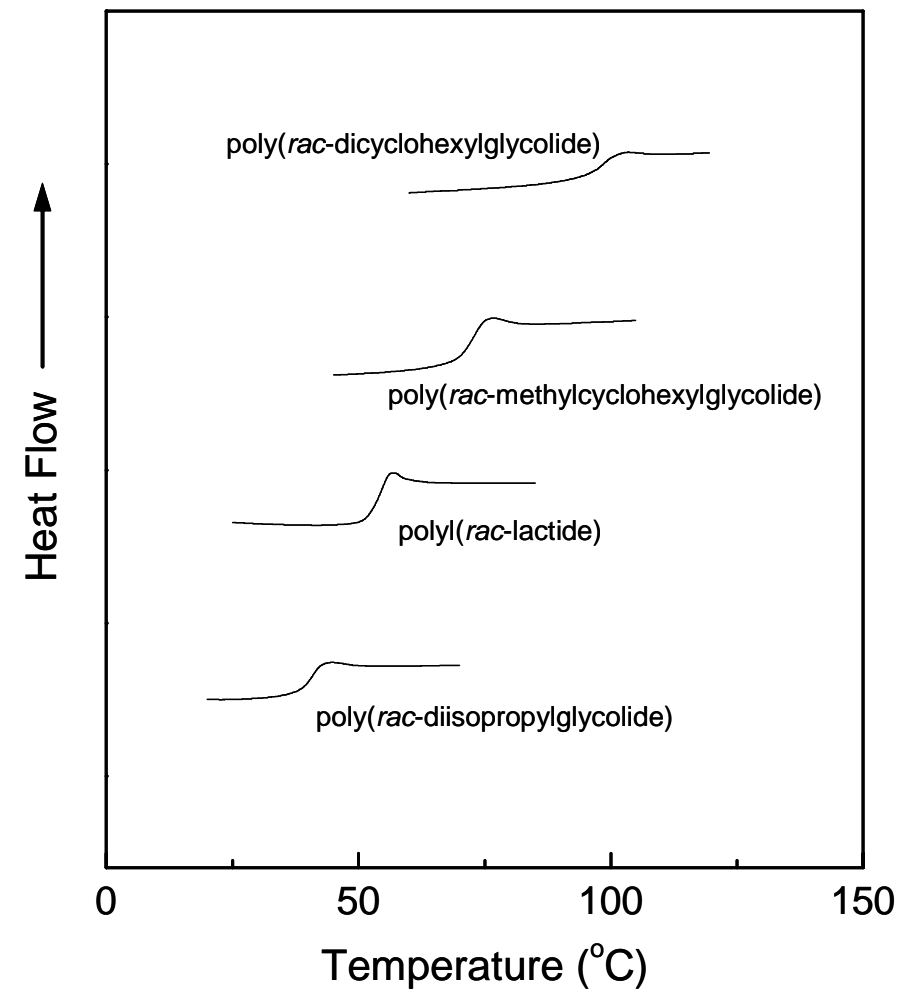

Figure S2. DSC runs (second heating scan after flash quenching from $120^{\circ} \mathrm{C}$ ) for substituted polyglycolides. Heating rate: $10^{\circ} \mathrm{C} /$ min under nitrogen. 


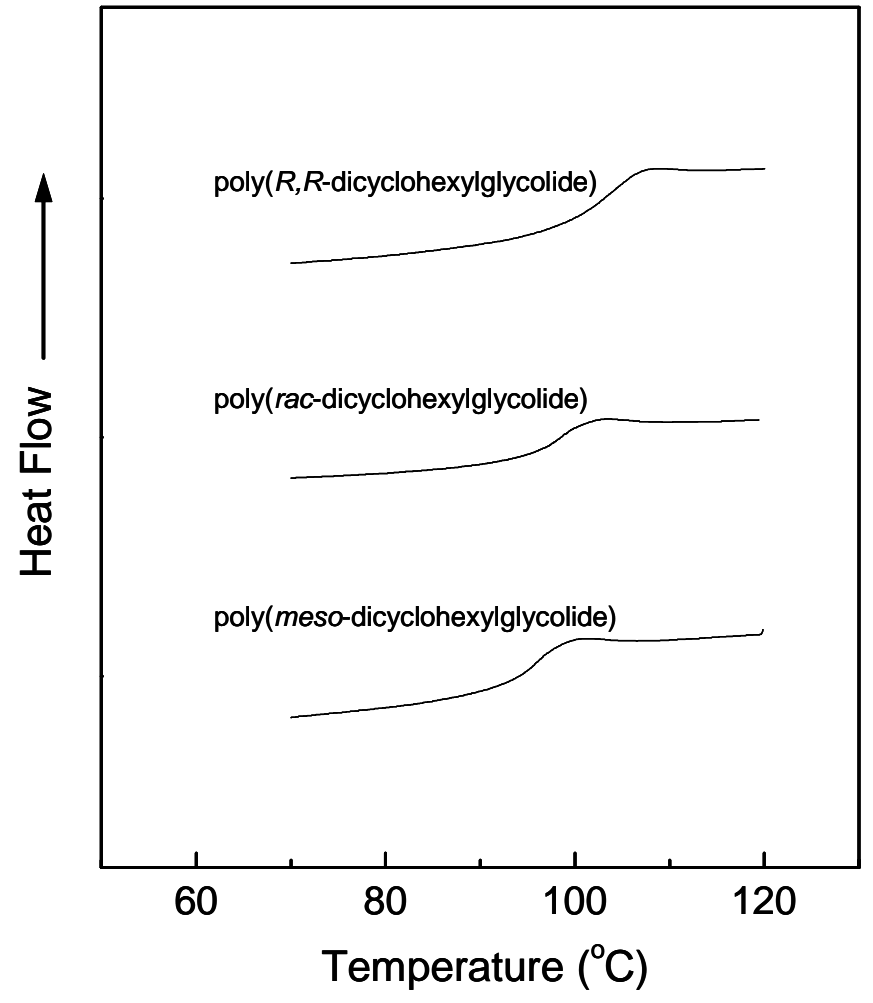

Figure S3. DSC runs (second heating scan after flash quenching from $120^{\circ} \mathrm{C}$ ) for poly(dicyclohexylglycolide)s. Heating rate: $10{ }^{\circ} \mathrm{C} / \mathrm{min}$ under nitrogen. 


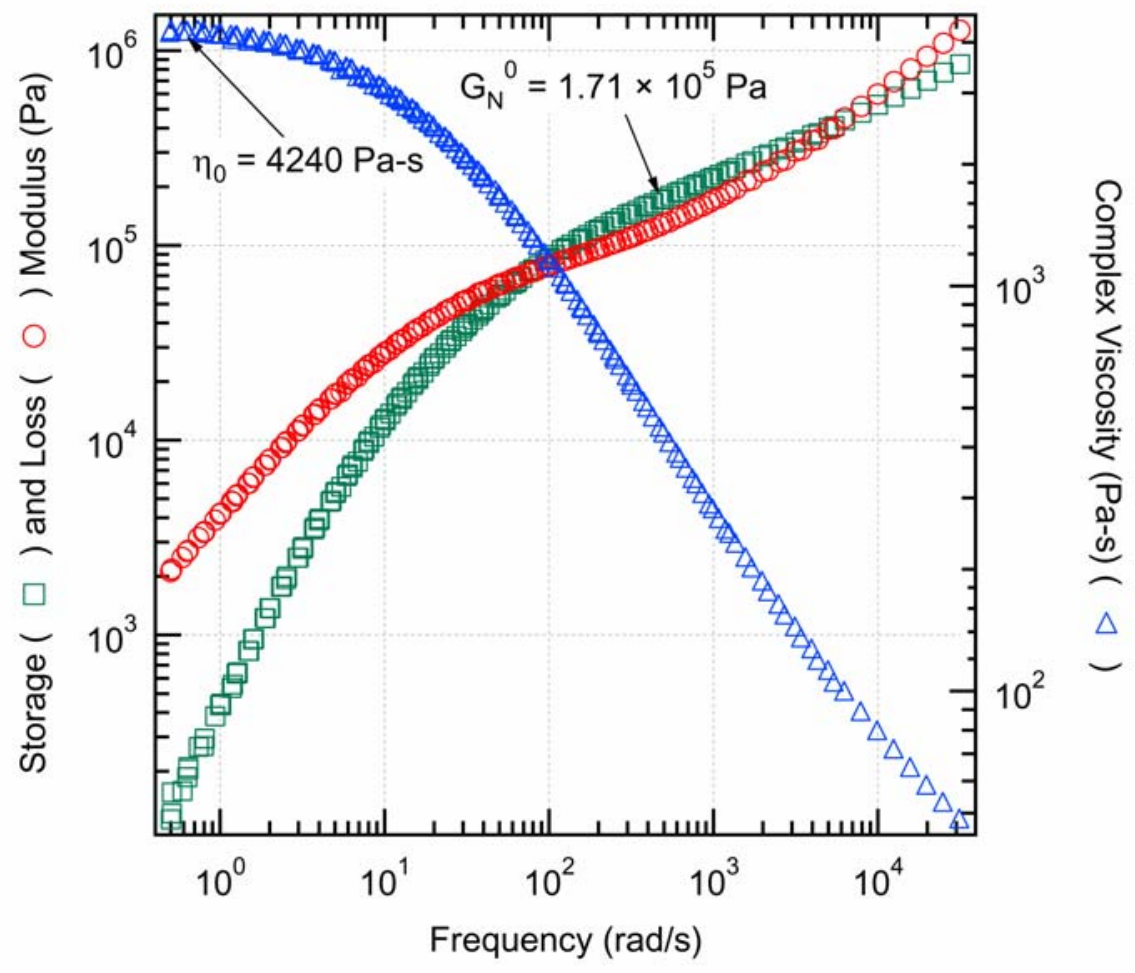

Figure S4. Linear viscoelastic properties of dicyclohexylglycolide at $170{ }^{\circ} \mathrm{C}(\mathrm{Mw}=85$ $\mathrm{Kg} / \mathrm{mol}, \mathrm{PDI}=1.46)$.

The viscoelastic properties of the polymer were characterized with an Rheometrics ARES rheometer using $8 \mathrm{~mm}$ diameter parallel plates to determine the storage ( $\left.\mathrm{G}^{\prime}\right)$ and loss $\left(\mathrm{G}^{\prime \prime}\right)$ moduli. All experiments were performed in the linear viscoelastic region and temperatures from 150 $200{ }^{\circ} \mathrm{C}$ were used and results shifted to a reference temperature of $170{ }^{\circ} \mathrm{C}$. The plateau modulus $\left(\mathrm{G}_{\mathrm{N}}{ }^{0}\right)$ was determined by equating the storage modulus to its value at the frequency corresponding to the minimum in the loss angle and the terminal viscosity $\left(\eta_{0}\right)$ was determined by extrapolation. 

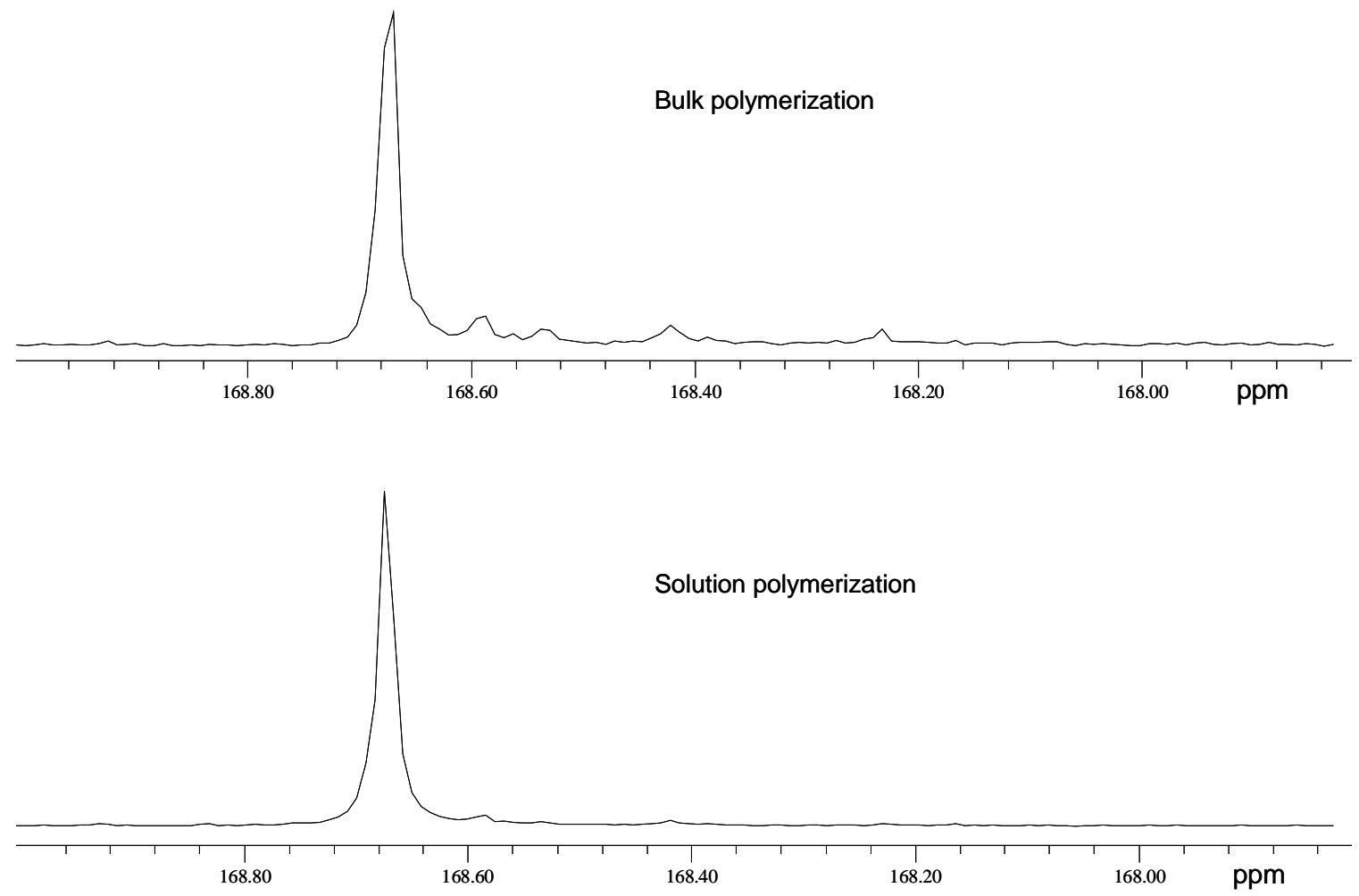

Figure S5. $125 \mathrm{MHz}{ }^{13} \mathrm{C}$ NMR spectrum of the carbonyl region for solution polymerized $R, R-$ dicyclohexylglycolide. 